\title{
Exploring the role of cognitive control in syntactic processing
}

Article

Accepted Version

Wolleb, A., Sorace, A. and Westergaard, M. (2018) Exploring the role of cognitive control in syntactic processing. Linguistic Approaches to Bilingualism, 8 (5). pp. 606-636. ISSN 18799272 doi: https://doi.org/10.1075/lab.17002.wol Available at https://centaur.reading.ac.uk/70820/

It is advisable to refer to the publisher's version if you intend to cite from the work. See Guidance on citing.

To link to this article DOI: http://dx.doi.org/10.1075/lab.17002.wol

Publisher: John Benjamins

All outputs in CentAUR are protected by Intellectual Property Rights law, including copyright law. Copyright and IPR is retained by the creators or other copyright holders. Terms and conditions for use of this material are defined in the End User Agreement.

\section{www.reading.ac.uk/centaur}

\section{CentAUR}

Central Archive at the University of Reading

Reading's research outputs online 


\title{
Exploring the role of cognitive control in syntactic processing: evidence from cross-language priming in bilingual children
}

\author{
Anna Wolleb, Antonella Sorace, Marit Westergaard \\ University of Reading, University of Edinburgh, UiT, the Arctic University of \\ Tromsø
}

In this paper, we explore the role of cognition in bilingual syntactic processing by employing a structural priming paradigm. A group of Norwegian-English bilingual children and an age-matched group of Norwegian monolingual children were tested in a priming task that included both a within-language and a between-language priming condition. Results show that the priming effect between-language was not significantly smaller than the effect within-language. We argue that this is because language control mechanisms do not affect the access to the shared grammar. In addition, we investigate the interaction between the children's performance in the priming task and in a nonlinguistic cognitive task and find that the two measures are not correlated; however, we find a correlation between the cognitive task and language control, which we measured by counting the number of trials produced in the non-target language. Our findings suggest that language control and domain-general executive control overlap only partially.

Keywords: Bilingual development, syntactic processing, structural priming

\section{Introduction}


In this study, we investigate how syntactic structures are represented and accessed in language production by bilingual children. In particular, we explore the role of cognitive control in the selection and use of these representations. To do so, we tested a group of Norwegian-English bilingual children and a group of age-matched Norwegian monolinguals in a priming paradigm and in a cognitive task. The different structures were elicited by means of a priming task (within- and between-language) where children were first exposed to alternating word orders (prime) and then had to describe a picture by selecting one of two possible options (target). In addition, we explored the correlation between the children's priming effect and their performance in a nonlinguistic cognitive task. Our goals are two-fold: first, to examine whether access to the abstract syntactic representations that are shared between languages is mediated by an inhibitory control mechanism; second, to establish whether language control and nonlinguistic executive control are completely separate or share some common features.

\section{Bilingual language processing and cognition}

The last twenty years have seen a flourishing of studies exploring the effects of bilingualism on cognition (see Bialystok, 1988; Carlson \& Meltzoff, 2008; Bialystok \& Viswanathan, 2009; Kroll \& Bialystok, 2013; Baum \& Titone, 2014; Cattaneo, Calabria, Marne, Gironell, Abutalebi \& Costa, 2015). From the resulting literature, we know that growing up with more than one language, but also, to some extent, learning a second language in adulthood, positively affects processes that are not specifically linguistic in nature, but belong to general cognition. In particular, researchers have 
focused on a set of abilities referred to as executive functions, whose neurological substrate is located in the frontal lobe of the human brain (Shallice, 1998). As proposed by Miyake and Friedman (2012), executive functions consist of at least three subcomponents: 1) switching, 2) monitoring and 3) inhibition. Switching is the ability to relocate attention between different tasks, operations or mental sets (Monsell, 1996). The monitoring function is the ability to constantly track the flow of information during a task and employ new data while ignoring old and no longer relevant data. Finally, inhibition has been characterised differently in different studies: first, as response inhibition, being the ability to override a dominant or prepotent automatic response in order to complete a particular task: and second, as interference suppression in bivalent tasks that present two conflicting dimensions and require focusing on one and ignoring the other (see Martin-Rhee \& Bialystok 2008).

The debate surrounding the impact of bilingualism on executive functions has so far led to controversial conclusions. Recently, a number of studies have reported that results indicating a bilingual advantage can be difficult to replicate (e.g., Costa, Hernández, Costa-Faidella \& Sebastián-Gallés, 2009, Paap \& Greenberg 2013; Valian 2015; Kroll \& Bialystok 2013). This is due a number of reasons: first, there are several factors other than bilingualism that may lead to an advantage in cognitive tasks, such as age, socio-economic status, general intelligence, computer game proficiency and many others; second, researchers tend to make a categorical distinction between monolingual and bilingual individuals, whereas it is becoming increasingly clear that bilingualism should be treated as a continuous variable (see Kroll \& Bialystok 2013); and third, performance in cognitive control tasks is often difficult to interpret. This is partly because the same task often tests not one but several different abilities, which makes it 
challenging to define a direct link between bilingualism and a particular cognitive component; and partly because tests that supposedly tap the same cognitive abilities often yield inconsistent results (see Valian 2015).

In fact, there is still no agreement on which specific component or components of the executive functions benefit from the bilingual experience. Seminal studies (e.g., Meuter \& Allport, 1999; Bialystok \& Martin, 2004; Carlson \& Meltzoff, 2008) singled out inhibitory control as the ability that was most affected by the coexistence of two languages in one brain. The reasoning behind this claim is that, at no time, is one of the two languages completely inactive in the bilingual brain, even if it is not being used in that particular moment. Therefore, the speaker needs to employ a mechanism that keeps attention focused on the relevant language and inhibits interference from the unwanted one. This mechanism is referred to as bilingual language control (Green, 1998; Green \& Abutalebi 2013). The assumption at the core of the bilingual advantage hypothesis is that bilingual language control shares some characteristics with non-linguistic executive control. If this assumption is true, then both language control and executive control should be highly developed in bilinguals thanks to the necessity to constantly operate two languages.

However, the focus of recent research has shifted to switching, monitoring, disengagement of inhibition, refocusing of attention, or post-conflict effects as possible areas where the impacts of bilingualism can be detected (Prior \& MacWhinney, 2010; Costa, Hernández, Costa-Faidella \& Sebastián-Gallés, 2009; Treccani, Argyri, Sorace \& Della Sala 2009; Grundy \& Chahi 2016). The hypothesis that bilinguals have better switching abilities assumes that bilingual speakers develop an enhanced ability to shift and refocus attention from task to task, and to and from different mental sets, as a result 
of their daily experience in switching from one language to another. In addition, an advantage in monitoring would derive from the bilinguals' need to constantly track the appropriate language they need to use in each communication.

Finally, more and more researchers are putting forward the claim that bilingualism shapes the brain in different ways and report results that are compatible with a multicomponent perspective of the bilingual advantage. Their claim is that differences in performance between bilinguals and monolinguals may result from a complex interplay of more than one executive control component (e.g., Bialystok, Craik \& Luk, 2012; Morales, Gomez-Ariza \& Bajo, 2013; Costa \& Sebastián-Gallés, 2014).

A further question that remains unanswered is whether language control and executive control are indeed involved in the same processes, or rather, if they do not overlap or if they do so only partially. Critics of the bilingual advantage go as far as claiming that bilingualism does enhance inhibitory control, monitoring and switching, but that the advantage may be language-specific and not generalizable to broader cognitive processes (e.g., Paap \& Greenberg, 2013); other researchers come to the more cautious conclusion that executive control in non-linguistic tasks and bilingual language control share some characteristics, but not all of them (see Calabria, Hernández, Branzi \& Costa, 2012; Calabria, Branzi, Marne, Hernández \& Costa, 2015; Cattaneo, Calabria, Marne, Gironell, Abutalebi \& Costa, 2015).

In this paper, we elaborate further on this topic, but we analyse the issue from a different point of view. Specifically, instead of examining the effects of bilingualism on general cognition, we investigate the role of general cognition in bilingual language processing. We assume that there is at least a partial overlap between language processing and non-linguistic cognition and that general cognition plays an important 
role in the way syntactic representations are accessed and processed in bilingual speakers (see also Sorace 2016). Note that this possibility is entertained not only by researchers working on bilingualism, but also by those whose work explores the relationship between cognitive control and parsing. Based on a review of neuroimaging and patient evidence, Novick, Trueswell and Thompson-Schill (2005) claim that the Left Inferior Frontal Gyrus (LIFG) is involved in conflict resolution and that this is the case for both linguistic and non-linguistic processes. In particular, the role of LIFG in syntactic processing is that of enabling reanalysis after misinterpretation, such as in the case of garden path recovery. Crucially, the authors argue that performance in nonlinguistic cognitive control abilities predicts performance in linguistic processing and in particular, in revision processes. Accordingly, recent studies suggest that sentence processing, and in particular garden-path recovery, can be improved by training nonlinguistic conflict resolution (see Novick, Hussey, Teubner-Rhodes, Harbison \& Bunting 2013). Crucially, Teubner-Rhodes, Mishler, Corbett, Andreu, Sanz-Torrent, Trueswell and Novick (2016) show that bilingual participants are more accurate than monolinguals in non-linguistic conflict resolution tasks and in sentence comprehension, both before and after training. These studies suggest that the relationship between general cognition and language is a complex one and that the processes involved in the two do share some common characteristics. Our study places itself in this line of investigation, but addresses the issue by employing structural priming as a research tool.

\section{Structural priming within- and between-language: activation and processing of shared syntactic representations}


Priming is defined as the tendency to reproduce the structure of a sentence that has recently been processed. Bock (1986) was the first to speculate that repetition was due to the activation of abstract syntactic structures, rather than to lexical similarity. In her experiments, participants were presented with a set of sentences and pictures and later asked to decide whether they had previously encountered them. The sentences alternated between active and passive and between double object (DO) and prepositional object (PO), as in (1) and (2).

(1) a. The chairman is suggesting a compromise

b. A compromise is being suggested by the chairman

(2) a. The secretary is baking a cake for her boss

b. The secretary is baking her boss a cake

Bock (1986) reports that participants were more likely to describe a picture using a structure that had been previously produced. Since then, this very robust phenomenon has been observed in several different experimental settings, from dialogue to sentence completion tasks to comprehension tasks (e.g., Cleland \& Pickering, 2003; Pickering \& Garrod, 2004; Gries 2005). Also, it has been studied in different languages and populations, including children and bilingual speakers (e.g., Loebell \& Bock, 2003; Bencini \& Valian, 2008; Hervé, Serratrice \& Corley, 2015). According to Branigan (2007), priming takes place because exposure to a stimulus has a facilitative effect on later processing of that same stimulus. In other words, priming decreases the cognitive load by directing the choice to one of many possible grammatical options. Interestingly, 
research shows that children are particularly susceptible to priming (Branigan, McLean \& Jones, 2005; Rowland, Chang, Ambridge, Pine \& Lieven, 2011). According to Branigan, McLean and Jones (2005), children have "weaker" syntactic representations than adults; thus, it is possible that priming facilitates the access to these representations, and especially to those that are more complex and normally acquired later. Alternatively, these results can also be explained in terms of implicit learning: repeated exposure to a structure facilitates subsequent production of that same structure by reinforcing the link between message and syntactic form. (see e.g., Ferreira 2003; Bock, Dell, Chang \& Onishi, 2007; Branigan, Pickering, Stewart \& McLean, 2000). Pickering and Branigan (1998) propose a model where syntactic priming can be explained in terms of residual activation. Based on the work of Dell (1986), Roelofs (1992) and Levelt, Roelofs and Meyer (1999), the model assumes the existence of a lemma stratum containing a lemma node for each lexical concept. The lemma nodes are linked to nodes at the conceptual stratum and at the word-form stratum, where phonology and morphology are specified. Furthermore, according to Roelofs (1992), the lemma stratum also contains syntactic property nodes (e.g., noun, verb), which are linked to the lemma nodes. Importantly, each syntactic category is represented by a single node. So, for example, both cat and shoe are linked to the N (noun) node. Pickering and Branigan (1998) modify Roelofs' (1992) model to incorporate features other than gender in the lexical entries, as well as syntactic and combinatorial information. Specifically, they identify three types of information that must be represented: category information (the syntactic category), featural information (number, gender, tense, aspect, etc.), and combinatorial information (the way in which a word combines with other linguistic units). For example, loves is associated with the 
syntactic category Verb, and the features specifying that it is present, third person and singular. Combinatorial information tells us that loves can combine with two NPs, as in "John loves cats".

Crucially, Pickering and Branigan (1998) argue that, in language production, whenever a lemma is activated, the corresponding categorical, featural and combinatorial nodes are also activated, as well as the links that connect them. What follows from this argument is that syntactic priming can be explained in terms of residual activation, that is, by the fact that the production of a word activates the associated nodes at the lemma stratum. Activation then gradually decays, but does not disappear immediately, so while the nodes are still active, they are more likely to be preferred in subsequent production. Furthermore, the combinatorial nodes are shared between lemmas. Thus, a priming effect is predicted to occur between different verbs, as a result of the activation of the shared combinatorial information. For example, the verbs show and give can both be used in two different structures. These are: the double object structure, with two Noun Phrases (show/give someone something); and the prepositional object structure, with a Noun Phrase and a Prepositional Phrase (show/give something to someone). When the verb show is used in the prepositional object structure, the combinatorial node NP, PP is activated along with the lemma node, increasing the likelihood of being activated also in combination with another lemma linked to it (such as give).

A growing body of research shows that priming can also take place between languages, even when the prime and target are not translation equivalents. Hartsuiker, Pickering and Veltkamp (2004) argue in favour of a shared-syntax account, according to which syntactic structures that are similar in two languages are represented only once in 
the bilingual grammar. Consistent with this hypothesis, Loebell and Bock (2003) report that it is possible to prime syntactic structures between two languages, but only if the prime and target are formed in the same way. Accordingly, Hartsuiker et al. (2004), found a priming effect for passive constructions in Spanish-English bilingual adults, whereas Bernolet, Hartsuiker and Pickering (2007) failed to find priming for complex noun phrases between English and Dutch. The explanation for these findings lies in the way the analysed structures are formed: that is, English and Spanish have similar passive structures (e.g., 'the cat was chased by the dog'; el gato fue perseguido por el perro), but English and Dutch form complex noun phrases differently. Specifically, Dutch places the verb at the end of sentences such as 'the car that is red' (so, literally, 'the car that red is'), while English does not.

Based on these findings, Hartsuiker et al. (2004) provide an extension of the network model proposed by Pickering and Branigan (1998), where lemmas of the two languages share the same categorical and combinatorial nodes. In addition, words are tagged for language. The process underlying crosslinguistic priming is therefore very similar to that underlying priming within-language: the activation of the lemma and of the combinatorial node causes the activation of the grammatical structure, which is unspecified for language. Consistently, the adapted model predicts priming to occur not only within L1 and within L2, but also from L1 to L2 and from L2 to L1 (here and elsewhere, by L1 and L2 we mean any two-language combination, where L1 is not necessarily the native or dominant language). The model however, does not make an explicit prediction about the relative strength of the effect within- and betweenlanguage. At least two studies have addressed this issue and come to diverging conclusions. Schoonbaert, Hartsuiker and Pickering (2007) investigated Dutch second 
language learners of English and found a comparable priming effect within- and between-language. In contrast, Cai, Pickering, Yan and Branigan (2011), who tested Cantonese-Mandarin bilingual speakers, report a stronger effect within-language than between-language. Cai et al. (2011) propose the idea that the language nodes act exactly like the other nodes in the model. That is, they activate when a language is spoken, causing in turn the activation of all lemmas of that language, which, according to Cai et al. (2011) is responsible for a within-language boost even in the absence of lexical overlap. The activation of a language node may indirectly cause the other language to be temporarily "blocked off". Thus, they continue, this inhibition mechanism could also be a contributing factor to the difference in strength between priming within- and across-language. Findings from Cai et al. (2011) suggest that there is an inhibitory mechanism involved in the access to the shared syntactic representations in a bilingual grammar, but the authors do not elaborate further on this issue.

\subsection{Priming in bilingual children}

Up to this day, only a handful of studies have been dedicated to priming in bilingual children. To our knowledge, these include Vasilyeva, Waterfall, Gámez, Gómez, Bowers and Shimpi (2010), Hsin, Legendre and Omaki (2013) and Hervé, Serratrice and Corley (2015). Vasilyeva et al. (2010) tested passive voice in 65 English-Spanish bilingual children aged 5;2 to 6;5 using bidirectional priming (English to Spanish and Spanish to English). The two languages have similar passive structures (e.g., 'The tree was broken by the lightning bolt'/El árbol fue quebrado por el rayo). However, the socalled fue-passive in Spanish is both formal and infrequent; instead the se-passive is 
more common in everyday language, but it does not have an English equivalent (e.g., Se quiebran los árboles, 'the trees are breaking'). Interestingly, the authors found a significant priming effect from Spanish to English, but not from English to Spanish. This means that the children produced significantly more passives in English after hearing fue-passives in Spanish, but did not produce any fue-passives in Spanish after hearing passive primes in English. However, they did produce some se-passives. Vasilyeva et al. (2010) propose that this asymmetry may result from the fact that fuepassives are infrequent in Spanish and normally only used in formal language. This means that, even if passives are shared in English and Spanish, their use seems to be mediated by pragmatic factors.

The study by Hsin et al. (2013) focuses on Noun-Adjective word order in 24 Spanish-English bilingual children aged $4 ; 0$ to 5;0. The authors argue that English only allows for prenominal adjectives (e.g., the open book), while in Spanish prenominal adjectives are ungrammatical (e.g., *el abierto libro, 'the open book'). Despite this difference, Hsin et al. found that the children were significantly more likely to produce adjective-noun forms in Spanish after hearing the same word order in English. This, they argue, shows that it is possible to prime a structure that is grammatical in L1 but ungrammatical in L2. Therefore, these findings call for a revision of the shared-syntax account as proposed by Hartsuiker et al. (2004), which holds that only structures that have the same word order are shared between languages. Instead, Hsin et al. propose that all abstract syntactic representations are shared, regardless of their word order.

However, while postnominal adjectives are by far the more frequent option in Spanish, prenominal adjectives are sometimes allowed (e.g., la bella Julia, 'the beautiful Julia'). This means that the Spanish grammar allows for both positions and 
that the prenominal word order is not ungrammatical, but rather infelicitous in most contexts.

Hervé et al. (2015) tested 38 French-English bilingual children, 19 of whom lived in France and 19 in the UK, and two groups of English and French monolingual children, on left dislocation in a priming paradigm. The children's ages ranged from $5 ; 4$ to $6 ; 7$. Both languages use left dislocation to mark topicality, although the phenomenon is more widespread in French. As argued by Hervé et al., the main difference between the two languages is that left dislocated elements tend to be old information in French, whereas left dislocation is used to introduce new referents in English. Therefore, there is structural overlap, but the factors governing the two variants differ across the two languages. In addition, the structure is much more frequent in French than it is in English. The four groups were tested in two picture-description tasks, one in French and one in English. The experiment was designed to create a pragmatic context that is less than optimal in English. That is, left dislocation was used in the prime to describe contrastive topics in English.

Results showed that both monolinguals and bilinguals produced a large number of left dislocations in French, whereas, in English, the bilingual children produced them rarely and the monolingual children produced none. Specifically, the priming effect was found to be significant in French and not in English, even though the children produced a larger number of left dislocations in English when the prime was a left dislocation than when it was not. In addition, the children's production of left dislocation varied depending on language exposure. That is, in French, children who had more exposure to French produced more left dislocation than children who were more exposed to English; 
similarly, in English, children with more exposure to English were less likely to produce left dislocation than the children who were more exposed to French.

Hervé et al. (2015) conclude that bilingual children are sensitive to the relative frequency of the structure in their languages; however, crosslinguistic influence takes place and increases as a function of language exposure; in addition, they suggest that priming can override discourse-pragmatic constraints in bilingual children, but not in monolingual children.

\section{Aims and predictions of the present study}

The phenomenon under investigation is dative alternation, which is present both in English and in Norwegian (see examples below).

(1) Mary showed the painting to a friend/Mary showed a friend the painting

(2) Mary viste maleriet til en venn/Mary viste en venn maleriet

However, despite their similarity, datives do not behave in exactly the same way in the two languages, as fewer classes of verbs in Norwegian than in English allow for the dative alternation. For this reason, we only included three verbs in the tests - give, show and sell - that consistently alternate between a double object and a prepositional object construction in both languages. Furthermore, as pointed out by Bresnan, Cueni, Nikitina and Baayen (2007), for English, the two constructions are not exactly interchangeable, but their selection depends on semantic and pragmatic factors. According to Collins (1995) and Rappaport-Hovav and Levin (2008), factors such as discourse status (given 
vs. new information) and animacy play a role in the choice of the dative variant. Thus, to avoid creating a bias towards one of the two structures, all prime-target picture pairs in the tests depicted two animated characters and were always described by the experimenter with definite determiners. Note, however, that in elicited production tasks, children tend to show a preference for the prepositional object (PO) variant, even in contexts where the double object (DO) would be pragmatically more appropriate. This phenomenon has been observed by Anderssen et al. (2012) for Norwegian and by Stephens (2010) for English. In Andersen et al. (2012), Norwegian children had a strong preference for POs, even in contexts where a DO would have been the pragmatically appropriate option. A possible explanation, they argue, lies in the syntactic representation of the two dative constructions. Tungseth (2006) proposes that the two constructions are derivationally related with PO being the underlying form. Therefore, it is possible that children up to a certain age prefer POs to DOs because syntactic movement requires a higher processing cost than the underlying word order.

The goals of this study are: (a) to directly compare between- and withinlanguage priming in a group of balanced bilingual children; (b) to investigate a possible correlation between language control and executive control by comparing the performance in a priming task with the performance in a non-linguistic cognitive task for children that recruits inhibitory control and cognitive flexibility; and (c) to compare the priming effect in the bilingual group with an age-matched monolingual control group. In a setting such as that of cross-language priming experiments, the level of the participants' bilingual language control (Green, 1998) is high, in order for them to answer as instructed in the target language after hearing a prime in the other. The same does not apply to within-language priming experiments, where both prime and target are 
uttered in the same language and therefore, the need to relocate attention is likely lower. This is analogous to the difference, in switching tasks, between single blocks, in which attention is always focused on the same dimension and the other has to be excluded, and mixed blocks, where what is inhibited in one trial may become a target in the next trial. On the other hand, Norwegian and English have equivalent structures for the two dative variants, and previous research shows that priming between two languages can be as strong as the effect within-language if the primed constructions are structurally similar (e.g., Schoonbaert, Hartsuiker \& Pickering 2007). Since priming occurs as a result of the activation of shared combinatorial nodes that are not language-specific, it is possible that the inhibition mechanisms triggered during cross-language priming do not prevent access to the shared syntactic information, but simply have the function of avoiding interference from the non-target language. Therefore, a stronger within-language effect would suggest, following Cai et al. (2011), that inhibitory control is in fact blocking access to the shared syntactic representations; instead, a comparable effect in the two conditions would show that bilingual language control does not prevent the activation and use of the shared syntactic structure.

In addition, we test the assumption that the kind of inhibition involved in nonlinguistic cognitive tasks shares at least some characteristics with bilingual language control. We do this in two ways: first, we explore the correlation between the priming task and a task testing executive function. Specifically, if inhibitory control weakens the access to the shared grammar, then those children who score better at the executive function task should also show a weaker between-language priming effect. On the other hand, if inhibitory control does not affect the activation of the primed structures, then there should be no correlation between the two tasks. Second, we examine the 
interaction between performance in the executive function task and the number of trials where children fail to respond in the target language, which we see as instances of language control failure. Here, a correlation between two measures would suggest that non-cognitive executive control and language control share some common mechanism. Our prediction is that those children with the lower scores in the non-linguistic task will produce the most responses in the non-target language during cross-language priming.

In sum, our goal is to contribute to the debate on the role of general cognition in bilingual language processing by testing Cai et al's (2011) argument that inhibition is involved in cross-language priming. The hypothesis assumes that the mechanisms involved in cross-language priming and in an executive control task at least partially overlap and it predicts that priming within-language should be weaker than priming between-language as a result of the involvement of an inhibitory mechanism; in addition, we argue that a correlation between the performance in the priming task and in the executive control task could be interpreted as evidence of an overlap between bilingual language control and executive control.

\section{Method}

\subsection{Participants}

A group of 38 Norwegian-English bilingual children were recruited. At the time of testing, ten of the children lived in Stavanger, 24 in Oslo and four in Troms $\varnothing$. All children in Stavanger attended the British School of Stavanger; 14 children in Oslo attended the Oslo International School, and the remaining ten were recruited through a 
group of international parents (International MOther and B Aby Group Oslo). In Troms $\varnothing$, two children attended the Troms $\varnothing$ International School and the other two were recruited through family friends. All children had lived in Norway at least three years and had at least one Norwegian-speaking parent. One child had to be excluded from the analysis because he was found to have very poor knowledge of Norwegian. The control group was composed of 28 monolingual Norwegian children. All children lived in Troms $\varnothing$. Of these, 12 attended a nursery, Universet Barnehage, and 16 attended an elementary school, Mortensnes Skole. Parental consent was obtained through written forms prior to the testing. All children received a small present for their participation in the games.

At the time of testing, the bilingual children were aged 55 to 101 months, or $4 ; 7$ to $8 ; 5(M=74.21 ; S D=15)$. The children's score in the Norwegian vocabulary test ranged from 63 to $116(M=90.94, S D=15.58)$; the children's score in English vocabulary ranged from 61 to $124(M=99 ; S D=12.07)$. In order to establish whether the two means differed significantly, a paired-sample t-test was carried out on the data. On average, the children had better scores in the English vocabulary test than in the Norwegian test $(t(36)=4.02 ; p=.0002)$. Parents were contacted and asked to report about their children's linguistic habits using the Utrecht Bilingual Language Exposure Calculator (UBiLEC) (Unsworth 2011). One of the three measures extracted from the questionnaire - current amount of exposure $(\mathrm{CaE})$ - was included in the analysis as a control variable. This was obtained by collecting information about the linguistic habits of the child at home, at school, and during after-school activities. For each situation, the parent was asked to indicate how often the target language (TL), in this case Norwegian, was used, as opposed to the other language (OL), in this case English. This 
value can range from 0 to $1(0 \%$ to $100 \%)$. The results from the questionnaire indicated that the children's CaE to Norwegian varied from 0.2 to $0.82(M=.45 ; S D=.19)$.

A Linear Mixed Model with Score in the Norwegian vocabulary as a dependent variable and Current Amount of Exposure $(\mathrm{CaE})$ as an independent variable revealed that $\mathrm{CaE}$ is significantly correlated with the Score in the Norwegian vocabulary test $(b=$ 32.66, $S E b=15.4, t(18)=2.12, p=.04)$. This indicated that the more everyday exposure the children got in Norwegian, the better their vocabularies were. A second analysis with English vocabulary as a dependent variable and $\mathrm{CaE}$ as an independent variable showed that there is no significant correlation between the score in English vocabulary test and the amount of exposure to Norwegian $(b=7.7, S E b=11.13, t(18)=$ $.69, p=.49)$.

The monolingual children were aged 55 to 96 months, or 4;7 to $8 ; 0(M=74.13$, $S D=19.62$ ). An independent-sample t-test showed that the age difference between the bilingual and the monolingual group is not significant $(t(64)=-.011, p=.9)$. Their score in the Norwegian vocabulary test ranged from 71 to $118(M=94.06 ; S D=10.79)$. An independent-sample t-test was carried out on the data to establish whether the monolingual and bilingual children differed in their Norwegian vocabulary. The results indicated that the two groups have comparable Norwegian vocabulary $(t(64)=-.88 ; p=$ $.4)$.

Data collection was carried out from September 2012 to February 2013. The investigator and a research assistant visited the children either at their school/nursery or in their homes. The children were told that they would be taken out of class, and that they would play a set of games in English and Norwegian with both investigators. The order in which the tests were administered was randomized across children. The 
investigator tested the children in English only, while the research assistant, who is a Norwegian-English bilingual speaker, tested the children in Norwegian.

\subsection{Tasks and Procedure}

\subsubsection{Priming task}

The main experiment was a picture-description task, where the investigator first described a picture (prime) and then the child described a similar, but not identical, one (target). Following Branigan et al. (2005) the task was designed as game of "Snap!". Each player was given a set of 20 cards, 16 of which were prime-target pairs and 4 of which were Snap cards. When the game started, the two players alternated in turning and describing pairs of cards. When the pair consisted of two identical cards, the first of the participants to shout "Snap!" would win the cards. The prime-target cards depicted an animal performing an action and a human recipient and could be described with the verbs give, sell or show, all of which allowed a double object construction (DO) or a prepositional object construction (PO); the snap cards depicted intransitive actions involving two characters, either animal or human. The investigator always described her card first and, in order to decide whether to use a DO or a PO, she read from one of four possible different scripts which had been previously prepared by pseudo-randomising both the order of the cards and the structure to be used in each case. Each script contained 50\% PO and 50\% DO prime descriptions. Crucially, no lexical item was ever shared between prime and target card pairs. The task included a within-language and a between-language condition. In the within-language condition, both the investigator and 
child played the game in Norwegian, whereas in the between-language condition, the investigator provided the prime in English and the child had to respond in Norwegian. The same set of cards was used for both conditions and each card was used only once in the same condition. We chose to explore cross-language priming in one direction only (i.e., English prime and Norwegian target) to reduce the total length of the experiment. The experiment was counterbalanced, so that half of the children played the within language condition first, and the other half played the between language condition first.

(3) Within-language condition

Player A: Sauen selger eplet til dronningen/Sauen selger dronningen eplet Sheep.def sells apple.def to queen.def/ Sheep.def sells queen.def apple.def "The sheep sells the apple to the queen/the seep sells the queen the apple"

Player B: Frosken viser...

Frog.def shows

"The frog shows..."

Between-language condition

Player A: The sheep is selling the apple to the queen/The sheep is selling the queen the apple

Player B: Frosken viser... Frog.def shows... "The frog shows..." 


\subsubsection{Dimensional Change Card Sort (DCCS)}

The DCCS (Zelazo \& Frye, 1998) is a game consisting of a set of cards depicting one of two objects (e.g., a rabbit or a boat) in two possible colours (e.g., red or blue). The game has a standard and a border version; half of the cards in the border version of the game have a black border surrounding the depicted object. The test consists of three phases: a demonstration phase, a pre-switch phase and a post- switch phase. In the demonstration phase (two trials), the investigator explains the rules of the game and gives feedback to the child. The child is asked to sort the cards according to one dimension (e.g., colour) and place them on sorting trays (e.g., blue cards on the left tray; red cards on the right tray). When the demonstration is over, the child moves to the pre-switch phase, where she follows the rules just learned without getting any feedback. After six trials, the child enters the post-switch phase, where she is instructed to ignore the previous rules and to change the sorting dimension to shape (e.g., rabbits on the left trays; boats on the right trays). The post-switch phase consists of six trials. If the children complete the postswitch phase without errors or with up to two errors, they move on to the border version of the game (designed for 7-year-olds or older), whereby they are instructed to sort the cards according to one dimension (e.g., colour) if there is a border present and according to the other dimension (e.g., shape) if there is no border present. The test starts after a demonstration phase (two trials), where the investigator explains the new rules and gives feedback to the child. The border version consists of 12 trials. Zelazo and Frye (1998) claim that in order to complete the task, children need to recruit both inhibitory control and cognitive flexibility. That is, they need to 1) in switch-trials, integrate the cue signalling switching, inhibit a previously valid but now obsolete 
response and select the correct one, and 2) be able to switch between sorting dimensions and refocus attention to carry out different operations on the same kind of stimuli. Figure 1 illustrates the different phases of the game in the standard and border versions.

<Insert Figure 1 about here>

Figure 1. Phases of the DCCS in the standard and border version

\subsubsection{Vocabulary task}

All children were tested in their Norwegian and English receptive vocabulary. To ensure that the two tests would be comparable, we chose The British Picture Vocabulary Scale 2nd edition (Dunn, Dunn, Whetton \& Burlett, 1997), which is the only available test that has been adapted for Norwegian (Lyster Halaas, Horn \& Rygvold, 2010). The BPVS consists of 14 sets of 12 different pictures, corresponding to 12 vocabulary entries. All sets contain pictures of comparable difficulty and are allocated to age levels, ranging from three to 15 . In the test, the first set is selected based on the age of the child and successive sets increase in difficulty. The test ends when the child has made eight or more mistakes in one set. During testing, the children are shown the pictures, hear the target word from the investigator and are instructed to point at the picture that corresponds to that word. The answer is noted on an answer sheet. In the Norwegian version, the same pictures are used, and, when possible, the words are translation equivalents of the English words (e.g., ladder/stige). Wherever a direct translation is not possible, the English word is either translated with a synonym, or a different picture from the same set is used instead. 


\subsection{Coding}

The different tasks were recorded and then transcribed and coded by the first author with the help of a Norwegian native speaker assistant. For the priming task, each trial was coded as a DO (e.g., hunden gir klovnen hatten; 'the dog is giving the clown the hat'), PO (e.g., hunden gir hatten til klovnen; 'the dog is giving a hat to the clown') or Other responses. For the between-language condition, responses given in English instead of Norwegian were coded as Noswitch. The DCCS consisted of a total of 24 trials (6 in pre-switch phase, 6 in the post-switch phase and 12 in the border version). The children that passed the post-switch phase were also asked to complete the border version. For each correct trial, one point was added to the score. The final score ranged from 0 (no correct trials in the post-switch phase) to 18 (all correct trials in post-switch phase and border version).

\section{Results}

In the within-language condition, the bilingual children correctly produced descriptions in 436 trials. Of these, 375 were prepositional objects (86\%) and 61 were double object constructions (14\%). In the between-language condition, the children correctly produced descriptions in 415 trials. Of these, 348 (84\%) were prepositional objects and $67(16 \%)$ were double object. The monolingual children correctly produced descriptions in 412 trials. Of these, $277(67 \%)$ were prepositional objects and $135(33 \%)$ were double object. Trials were excluded from the analysis if they did not contain either of 
the two relevant structures. Table 1 shows the mean proportion of double objects that were produced in each priming condition by the bilingual children.

The children's score in the DCCS ranged from 0 to $18(M=11.7 ; S D=6.13)$. A score of 0 means that the child failed the post-switch phase; a score of 6 indicates that the child passed the post-switch phase with a perfect score but failed the border version of the game. A score of 18 indicates that the child passed the border version with a perfect score.

<Insert Table 1 about here>

In order to explore the relationship between priming (henceforth referred to as Score) and various potential predictors, we conducted a series of step-wise regression analyses using the lme4 package in R 3.0.3 (Bates, Maechler, Bolker \& Walker, 2013). We carried out two separate Linear Mixed Models fit by maximum likelihood where the production of DOs was the dependent variable. Age, Vocabulary, Current Amount of Exposure, DCCS, Language (i.e., the language in which the prime was given) and Prime (PO or DO) were treated as fixed effects. In addition, the intercepts, Language and Prime, varied randomly across participants. The first analysis included data from the bilingual group only, whereas the second one compared the within-language condition from the bilingual data and the control group of Norwegian children.

Finally, in a third analysis, we explored the relationship between Noswitch and DCCS. Here, the dependent variable is the rate of Noswitch and the independent variable is the score at the DCCS. Also, we included Vocabulary and Current Amount of Exposure as control variables. 


\subsection{Analysis 1: Bilingual group}

With this analysis, we address goals (a) and (b) described above. The variables included as predictors in the analysis are the following:

- $\quad$ Prime (DO, PO);

. Language: the language in which the prime is given (Norwegian or English)

- DCCS: the score ranging from 0 to 18 ;

. Age;

. Norwegian and English vocabulary: the score obtained in the BPVS 2nd edition in the two languages;

. CaE: the score obtained in UBiLEC, ranging from 0 to 1 and indicating the child's current amount exposure to Norwegian.

As illustrated in Table 2, Score varies only depending on the kind of Prime. This means that children produce more DOs after a DO prime than after a PO prime. None of the other predictors are significantly correlated with Score. Also, there is no significant interaction between the kind of prime and the language in which the prime was given.

<Insert Table 2 about here>

\subsubsection{Summary}


The reported results indicate a reliable priming effect in both language conditions, where children produced significantly more DOs after hearing a DO prime than after hearing a PO prime. The effect between-language is marginally smaller than withinlanguage, but this difference does not reach significance (see Figure 2). Accordingly, Prime (DO, PO) is the only significant predictor. This suggests that the only factor influencing the production of a DO by the children is the structure of the sentence previously heard, namely whether they hear a PO or a DO prime. Cohen's effect size value, when separating out the observations into two language groups, suggests a moderate to large practical significance $(d=0.6)$. Alternatively, it could also be said that hearing DO in either language increases the likelihood of producing a DO in Norwegian by $13 \%$.

In addition, there does not seem to be a direct correlation between the strength of the priming effect and the score obtained by the bilingual children in the DCCS. What this means is that these data cannot support the hypothesis that children who have a stronger inhibitory control and better cognitive flexibility are also primed less betweenlanguage.

<Insert Figure 2 about here>

Figure 2: Mean proportion of double object responses in bilingual children in the within-language and between-language condition

\subsection{Analysis 2: Bilingual group vs. Monolingual group}


With this analysis, we address goal (c) described above. The variables included are the following:

. Prime;

. Group (bilingual, monolingual);

. Age;

. Norwegian vocabulary;

As reported in Table 3, Score varies depending on Prime, which means that the children produce more DOs following a DO prime than following a PO prime. The main effect of Group is significant, showing that monolingual children produce more DOs overall. Further, for the effect size of Group, Cohen's value $(d=0.75)$ suggests a large practical significance, while it could also be said that the likelihood of producing a double object is $19 \%$ higher in monolinguals. However, the interaction between Group and Prime is not significant, indicating that the priming effect is comparable in monolingual and bilingual children. Moreover, Age is negatively and significantly correlated to Score, indicating that younger children show a stronger priming effect than older children.

<Insert Table 3 about here>

\subsubsection{Summary}

Consistently with the bilingual data, the kind of prime (DO, PO) is a significant predictor of the score in the priming test. Monolingual children produce more DOs than 
bilingual children overall, but, the interaction between bilingual and monolingual children display comparable priming effects (see Figure 3). Accordingly, Group is a significant predictor of the production of DOs, but the interaction between Group and Prime is not significant. In addition, Age is significantly correlated to the Score, suggesting that younger children, regardless of the language group, are more subject to priming.

<Insert Figure 3 about here>

Figure 3: Mean proportion of double object responses in bilingual children in the within-language condition and in monolingual children

\subsection{Analysis 3: Interaction between Noswitch and DCCS}

In the priming task, children produced an average of 2 Noswitch trials, ranging between 0 and 10 , which equals $10 \%$ of the total trials $(n=619)$. Most children only produced Noswitch responses in Snap trials: six children produced a Noswitch response after a DO or PO prime, for a total of 17 trials (five DOs and 12 POs). All DO responses were preceded by a DO prime. Of the children who produced no Noswitch trials $(n=14)$, none failed the post-switch version of the DCCS and three failed the border version (21\%). Of the children who produced at least one Noswitch trial $(\mathrm{n}=19)$, two failed the postswitch version (11\%) and eight failed the border version (42\%).

With this analysis, we try again to address goal (b). The variables included in this analysis are the following:

. DCCS; 
. $\mathrm{CaE}$;

. Norwegian and English vocabulary;

As shown in Table 4, DCCS is negatively and significantly correlated with Noswitch. This indicates that children who have lower scores at the DCCS also fail to respond in Norwegian more often. None of the other variables are significantly correlated with Noswitch. However, Cohen's effect size value $\left(f^{2}=0.23\right)$ suggests a small practical significance, which alternatively can be stated as that passing the border version of the DCCS creates a decreased likelihood of producing a Noswitch trial by $19 \%$.

$<$ Insert Table 4 about here>

\subsubsection{Summary}

We reported above that there is no significant correlation between the priming effect and DCCS: nevertheless, a correlation was found when investigating the relationship between language control and inhibitory control using a more transparent measure for language control, namely the number of target trials uttered in the non-target language (i.e., English). Specifically, children with a lower score in the DCCS were more likely to produce target trials in English instead of Norwegian. Figure 4 below illustrates the interaction between Noswitch and DCCS, including data from the children who produced at least one Noswitch trial.

<Insert Figure 4 about here> 
Figure 4. Interaction between DCCS and Noswitch

\section{Discussion}

In this study we explore the relationship between cognitive control and syntactic processing by testing a group of bilingual children in a structural priming paradigm and comparing the effect in a within-language and a between-language condition.

Following Cai et al. (2011), we propose that a stronger within-language priming effect would suggest the involvement of an inhibitory control mechanism. In betweenlanguage priming tasks, participants listen to a stimulus in one language and have to answer in the other. In order to answer in the target language, they need to monitor their performance very closely and constantly inhibit the urge to answer in the language they hear from their counterpart. This is revealed clearly by the fact that sometimes the mechanism fails and the answer is given in the target-deviant language. This process resembles the every-day experience of bilingual speakers, who constantly need to focus their attention on the language that is being used and at the same time inhibit interference from the unwanted one. If this is true, in a between-language priming setting, the inhibitory mechanism should also affect the activation of the syntactic representations that are shared between languages, thus diminishing the strength of the effect. An opposing argument could be that during cross-language priming, the shared syntactic representations that are activated are unspecified for language and therefore are not affected by inhibitory mechanisms. That is, language control prevents interference from the non-target language, but it does not block access to the shared grammar. Our data seem to lend support to this last claim, as we find that the priming effect is comparable in within- and between-language. Another possibility is that 
inhibitory mechanisms only prevent access to the shared syntactic representations when the prime and target are not an equally good option in the two languages. Accordingly, Vasilyeva et al. (2010) were not able to prime fue-passives from English to Spanish and Hervé et al. (2015) report that the effect of priming is significantly weaker when the primed structure is not pragmatically felicitous in the target language. In the latter study, English-French bilinguals produced pragmatically odd left-dislocations in English as a result of priming, but the effect was significantly weaker than in French, where priming did not lead to the production of inappropriate forms. Based on this evidence, we suggest that language control may affect the activation of the abstract grammar only when the alternating word orders have different pragmatic interpretations in the two languages.

Interestingly, younger children show a stronger priming effect than older children, even though this difference is only significant when comparing the bilingual and the monolingual groups, but not within the bilingual group. Recall that Branigan et al. (2005) found that children are more easily primed than adults. They propose that children may have "weaker" syntactic representations than adults and are therefore more susceptible to the influence of previous experience when choosing what syntactic structure to use. Indeed, if priming acts as a facilitative tool in favouring the access to the shared syntactic representations, it is plausible that younger children benefit more from its effects than older children. In addition, these findings are compatible with the view of priming as an implicit learning tool. As argued by Ferreira (2003) among others, repeated exposure to a structure facilitates its subsequent production by reinforcing the link between message and syntactic form. Again, our results are 
compatible with the notion that younger children show greater learning than older children.

It is important to note that the monolingual Norwegian control group performed similarly to the bilingual group in the within-language condition. That is, the strength of the priming effect was not significantly different in the two groups. This indicates that bilingualism per se does not have an effect on priming, because if that were the case, then bilingual children should perform differently from the monolingual children in the within-language condition, and they do not. However, as we mentioned above, the Norwegian monolingual children produce significantly more DOs than the bilingual children overall (43\% vs. $20 \%$ ). Similarly, Anderssen, Rodina, Mykhaylyk and Fikkert (2012) find that Norwegian children aged 4;2 to 6;0 strongly prefer POs over DOs in elicited production tasks. These results are in line with those of several experimental studies conducted on English monolingual children (e.g., Conwell \& Demuth, 2007; Stephens, 2010). Anderssen et al. (2012) explain this phenomenon by claiming that children at that age still tend to avoid syntactic movement, and therefore tend to stick to the underlying form, which, as proposed by Tungseth (2006), is the PO for Norwegian. If we accept this explanation, we could speculate that bilingual children resist syntactic movement even more strongly than their monolingual peers (see also Westergaard \& Anderssen 2015).

Recall that bilingual children had better vocabulary scores in English than Norwegian. This means that the direction of cross-language priming went from their more dominant language (English) to their less dominant one (Norwegian). Even though vocabulary scores did not turn out to be significantly correlated to the priming effect, one is left to wonder what would have happened if the task had been 
administered in the opposite direction. It is possible that children would have produced fewer Noswitch trials; also that they may have behaved more like the Norwegian monolinguals and produced more DOs in total.

In order to directly investigate the relationship between executive control and priming, we look for a correlation between performance in the between-language priming task and in the DCCS, which is known to recruit inhibitory control and cognitive flexibility. This choice is based on the hypothesis that the two tasks may require similar abilities. That is, between-language priming occurs because the syntactic representations that are shared between two languages, and that are activated by previous experience, stay active for a certain amount of time and influence subsequent production. This process takes place in a context where the bilingual mind is working to control attention to the relevant language (i.e., the language in which the participant is expected to respond) and to inhibit the other one (i.e., the language in which the prime is given by the experimenter). Thus, our hypothesis was based on the notion that the abilities that are needed to succeed at the DCCS are the same as the ones employed in between-language priming to avoid interference from the irrelevant language. Also, we predict that inhibitory control would "block off" the access to the shared syntactic structure, resulting in smaller priming effect between-language. Finally, we propose that a correlation between the two tasks can be interpreted as evidence for an overlap between bilingual language control and inhibitory control. Specifically, we were expecting those children who scored higher in the cognitive task to show a weaker priming effect between-language. As the analysis shows, this is not the case, suggesting that the executive control ability needed to perform well on the DCCS task does not 
seem to be involved in restricting access to the target language during cross-language priming.

This brings us back to the issue of clarifying the relationship between nonlinguistic executive control and bilingual language control. Some recent studies on bilingualism and cognition (e.g., Paap \& Greenberg, 2013) claim that bilingualism does enhance inhibitory control, monitoring and switching, but that the effect is languagespecific and does not extend to broader cognitive processes. Based on the data in our study, we can come to more nuanced conclusions. First, we argue that betweenlanguage priming requires a particularly high level of language control, which prevents the participant from responding in the irrelevant language. However, this does not affect the access to the shared grammar, as shown by the fact that between-language priming is not significantly weaker than within-language priming. The lack of correlation between the strength of priming and DCCS suggests that a better inhibitory control does not predict a weakened activation of shared abstract representations, at least when the primed structures are equivalent in the two languages.

However, we do find a correlation between the results of the DCCS and Noswitch, that is the number of target trials that were produced in English instead of Norwegian. It seems to be the case that Noswitch is a more transparent measure of language control than the between-language priming effect. Indeed, resistance to priming between-language can be caused by a number of different variables, such as age and language proficiency. Instead, Noswitch trials clearly represent instances of the child's failure to employ language control. As expected, DCCS and Noswitch are negatively correlated, indicating that the children with lower scores at the DCCS are more likely to produce trials in the non-target language. More specifically, the children 
who produced more Noswitch trials were more likely to have failed the border version of the DCCS than the children who produced fewer or no Noswitch trials. Also, of those children who produced at least one Noswitch trial, the ones with lower DCCS scores produced more Noswitch trials than those with higher DCCS scores.

Thus, on the basis of these findings, our proposal can be formulated as follows: language control is recruited during between-language priming to allow the speaker to produce the target in language 1 after hearing the prime in language 2. However, it does not affect the activation of the shared grammar, resulting in a comparable priming effect in the two conditions. We offer two possible explanations: first, we speculate that the activated abstract representation for datives is not specified for language and therefore is not affected by language control mechanisms during bilingual exchanges; second, based on previous findings (Hartsuiker et al. 2004; Vasilyeva et al. 2010; Hervé et al. 2015), we argue that structural similarity and pragmatics play a crucial role in crosslanguage priming. Also, language control and executive control overlap, but only partially. This fact emerges from the lack of correlation between DCCS and priming, and from an existing correlation between the score of the DCCS and the rate of Noswitch. Importantly, this proposal is consistent with recent work by Calabria and colleagues, who suggest that language control and executive control share common features but do not overlap completely (Calabria, Hernández, Branzi, \& Costa, 2012; Calabria, Branzi, Marne, Hernández \& Costa, 2015; Cattaneo, Calabria, Marne, Gironelli, Abutalebi \& Costa, 2015).

\section{Conclusion}


The main objective of this study is to contribute to the ongoing debate on the role of executive function in syntactic processing and on the similarities and differences between bilingual language control and non-linguistic executive control. We address this question by investigating cross-language priming in balanced bilingual children, which is an under-studied research field. The network model proposed by Pickering and Branigan (1998) and adapted to bilingualism by Hartsuiker, Pickering and Veltkamp (2004) predicts that priming should occur across languages as a result of the residual activation of the abstract syntactic representations that are shared between languages. Our data confirm this prediction and show that the effect of priming between-language is not significantly different from the effect within-language. Note that this is contrary to Cai, Pickering and Branigan (2011), who report a significantly smaller betweenlanguage priming effect and propose that an inhibitory mechanism active during crosslanguage priming is responsible for this outcome. Instead, we argue that the shared grammar that is activated during priming is not specified for language and therefore is not affected by inhibitory mechanisms. Another possible explanation is that inhibition is not recruited because dative constructions are similar in Norwegian and English: previous research shows that priming occurs between two languages only if the prime structures have the same word order, which is the case for the forms tested in our study; in addition, Vasilyeva et al. (2010) and Hervé et al. (2015) show that priming is not equally effective when the primed word order leads to pragmatically odd structures in the target language. Based on this evidence, we suggest that inhibition is only triggered when there is a structural or pragmatic mismatch between the prime and the target language. 
In addition, we aim at establishing whether cross-language priming requires the same abilities that are needed during a non-linguistic interference task, or whether this inhibitory mechanism is language-specific. The answer to this question reflects the complexity of this issue and can be summarised as follows: the lack of correlation between performances in priming and in the cognitive task suggests that different processes are at work during the two tasks. However, a significant correlation between the cognitive task and the number of trials uttered in the non-target language by the children lends support to the idea that language control and executive function share common features even if they do not overlap fully.

In our view, this study constitutes a contribution to the field of bilingual development in two ways: first, it confirms that the syntactic representations of two languages can be shared in a bilingual mind and that this is true for adults as well as for children; second, it shows that the access to these representations is not affected by inhibition, even though language control is definitely recruited during cross-language priming tasks. The relationship between bilingualism and the executive function is a multifaceted one. We think these results can be interpreted as evidence that language control is at work during communication, especially in bilingual contexts. However, it remains unclear what exactly constitutes language control and what it has in common with domain-general executive control. There seems to be a separation between processes affecting the activation of the two languages as a whole and mechanisms regulating the access to the shared grammar. As long as the outcome is not ungrammatical or pragmatically odd, inhibiting the non-target language does not result in weakened activation of the abstract syntactic structures and therefore results in smaller priming effect. Our data clearly do not support the hypothesis that language 
control and executive control are one and the same, while at the same time also not supporting the hypothesis that they are two completely separate abilities. As Calabria and colleagues have suggested, the two domains overlap to some extent while maintaining distinct features. Future research should attempt to investigate more precisely where the two processes overlap, and where they differ. 
References

Anderssen, M., Fikkert, P., Mykhaylyk, R. \& Rodina, Y. (2012). Dative alternation in child Norwegian. Nordlyd, 39(1), 24-43.

Bates, D., Maechler, M., Bolker, B. \& Walker, S. (2013). Package 'lme4'.

Baum, S. \& Titone, D. (2014). Moving toward a neuroplasticity view of bilingualism, executive control and aging. Applied Psycholinguistics, 35, 857-894.

Bencini, G. M. L. \& Valian, V. (2008). Abstract sentence representations in 3-year-olds: evidence from language production and comprehension. Journal of Memory and Language, 59, 97-113.

Bernolet, S., Hartsuiker, R. J. \& Pickering, M. J. (2007). Shared syntactic representations in bilinguals: Evidence for the role of word-order repetition. Journal of Experimental Psychology: Learning, Memory, and Cognition, 33, 931-49.

Bialystok, E. (1988). Levels of bilingualism and levels of linguistic awareness. Developmental Psychology, 24, 560-567.

Bialystok, E., Craik, F. I. M. \& Luk, G. (2008). Cognitive control and lexical access in younger and older bilinguals. Journal of Experimental Psychology: Learning, Memory and Cognition, 34, 859-873.

Bialystok, E. \& Martin, M. M. (2004). Attention and inhibition in bilingual children: Evidence from the dimensional change card sort task. Developmental Science, 7(3), 325-339.

Bialystok, E. \& Viswanathan M. (2009). Components of executive control with advantages for bilingual children in two cultures. Cognition, 112, 494-500. 
Bock, K. (1986). Syntactic persistence in language production. Cognitive Psychology, 18, $355-387$.

Bock, K., Dell, G., S., Chang F. \& Onishi, K., H. (2007) Persistence structural priming from language comprehension to language production. Cognition, 104(3), 437458.

Branigan, H. P. (2007). Syntactic priming. Language and Linguistic Compass, 1(1-2), $1-16$.

Branigan, H. P., McLean, J. F. \& Jones, M. G. (2005). A blue cat or a cat that is blue? Evidence for abstract syntax in young children's noun phrases. In A. Brugos, M. R., Clark-Cotton, M. \& S. Ha (eds.), Proceedings of the $29^{\text {th }}$ Boston University Conference on Language Development, pp. 109-121. Somerville, MA: Cascadilla Press.

Branigan, H. P., Pickering M. J., Stewart, A. J. \& McLean, J. F. (2000) Syntactic priming in spoken production: Linguistic and temporal interference. Memory and Cognition, 2;28(8), 1297-1302.

Bresnan, J., Cueni, A., Nikitina, T. \& Baayen, H. (2007). Predicting the dative alternation. In G. Bouma, I. Kraemer \& J. Zwarts (eds.), Cognitive foundations of interpretation, pp. 69-94. Amsterdam: Royal Netherlands Academy of Science.

Cai, Z., Pickering, M. \& Branigan, H. P. (2011). Lexical and syntactic representations in closely related languages: evidence from Cantonese-Mandarin bilinguals. Journal of Memory and Language, 65(4), 421-445. 
Calabria, M., Branzi, F. M., Marne, P., Hernández, M. \& Costa, A. (2015). Age-related effects over bilingual language control and executive control. Bilingualism: Language and Cognition, 18(1), 65-78.

Calabria, M., Hernández, M., Branzi, F. M., \& Costa, A. (2012). Qualitative differences between bilingual language control and executive control: Evidence from taskswitching. Frontiers in Psychology, 2, 399.

Carlson, S. M. \& Meltzoff, A. N. (2008). Bilingual experience and executive functioning in young children. Developmental Science 11(2), 282-298.

Cattaneo, G., Calabria, M., Marne, P., Gironell, A., Abutalebi, J. \& Costa. A. (2015). The role of executive control in bilingual language production: a study with Parkinson's disease patients. Neuropsychologia, 66, 99-110.

Cleland, A.A. \& Pickering, M. J. (2003). The use of lexical and syntactic information in language production: Evidence from the priming of noun phrase structure. Journal of Memory and Language, 49, 214-230.

Collins, P. (1995). The indirect object construction in English: an informational approach. Linguistics, 33, 35-49.

Conwell, E. \& Demuth, K. (2007). Early syntactic productivity: Evidence from dative shift. Cognition, 103, 163-79.

Costa, A., Hernández, M., Costa-Faidella, J. \& Sebastián-Gallés, N. (2009). On the bilingual advantage in conflict processing: Now you see it, now you don't. Cognition, 113, 135-149.

Costa, A. \& Sebastián-Gallés, N. (2014). How does the bilingual experience sculpt the brain? Nature Reviews Neuroscience, 15, 336-345. 
Dell, G. S. (1986). A spreading activation model of retrieval in sentence production. Psychological Review, 93, 283-321

Dunn, Lloyd M., Dunn, Leota M., Whetton, C. \& Burlett, J. (1997). The British Picture Vocabulary Scale $2^{\text {nd }}$ Edition. London: GL Assessment Limited.

Ferreira, V. S. (2003). The processing basis of syntactic persistence: we repeat what we learn. Presented at the $44^{\text {th }}$ Annual Meeting of the Pshychonomic Society. Vancouver, Canada.

Green, D. W. (1998). Mental control of the bilingual lexico-semantic system. Bilingualism: Language and Cognition, 1, 67-81.

Green, D. W. \& Abutalebi, J. (2012). Language control in bilinguals: The adaptive control hypothesis. Journal of Cognitive Psychology, 25(5), 515-530.

Gries, S. (2005). Syntactic priming: a corpus-based approach. Journal of Psycholinguistics Research 34, 365-399.

Grundy, J. G. \& Chahi, A. K. (2016). Post-conflict slowing effects in monolingual and bilingual children. Developmental Science, 1-12. doi: 10.1111/desc.12488. Published online by Wiley-Blackwell, October 2016.

Hartsuiker, R. J., Pickering, M. J. \& Veltkamp, E (2004). Is syntax separate or shared between languages? Cross-linguistic syntactic priming in Spanish-English bilinguals. Psychological Science, 6 (15), 409-414.

Hernández, M., Martin, C., D., Barceló, F. \& Costa, A. (2013). Where is the bilingual advantage in task-switching? Journal of Memory and Language, 69, 257-276.

Hervé, C., Serratrice, L. \& Corley, M. (2015). Dislocations in French-English bilingual children: an elicitation study. Bilingualism: Language and Cognition. 
doi:10.1017/S1366728915000401. Published online by Cambridge University Press, July 2015.

Hsin, L. Legendre, G. \& Omaki, A. (2013). Priming Cross-linguistic interference in Spanish-English bilingual children. BUCLD 37 Proceedings. Somerville, MA: Cascadilla Press.

Kroll, J. F. \& Bialystok (2013). Understanding the consequences of bilingualism for language processing and cognition. Journal of Cognitive Psychology, 25, 497514.

Levelt, W. J. M., Roelofs, A. \& Meyer, A. S. (1999). A theory of lexical access in speech production. Behavioral and Brain Sciences, 22, 1-75.

Loebell, H. \& Bock, K. (2003). Structural priming across languages. Linguistics, 41 (5), $791-824$

Lyster Halaas, S. A., Horn, E. \& Rygvold, A. L. (2010). Ordforråd og ordforrådutvikling hos norske barn og unge. Resultater from en utprøving av British Picture Vocabulary Scale II, Second Edition (BPVS II). Spesialpedagogikk, 74(9), 35-43.

Martin-Rhee, M. M. \& Bialystok, E., (2008). The development of two types of inhibitory control in monolingual and bilingual children. Bilingualism: Language and Cognition, 11(1), 81-93.

Meuter, M. F. I. \& Allport, A. (1999). Bilingual language switching in naming: asymmetrical cost of language selection. Journal of memory and language, 40, $25-40$. 
Miyake, A. \& Friedman, N. P. (2012). The nature and organization of individual differences in executive functions: Four general conclusions. Current Directions in Psychological Science, 21, 8-14.

Monsell, S. (1996). Control of mental processes. In V. Bruce (ed.). Unsolved mysteries of the mind: tutorial essays in cognition, pp. 93-148. Hove, UK: Erlbaum.

Morales, J., Gómez-Ariza, C. \& Bajo, M. T. (2013). Dual mechanisms of cognitive control in bilinguals and monolinguals. Journal of Cognitive Psychology, 25(5), $531-546$.

Novick, J. M., Trueswell, J. C. \& Thompson-Schill, S. L. (2005). Cognitive control and parsing: Reexamining the role of Broca's area is sentence comprehension. Cognitive, Affective and Behavioral Sciences, 5(3), 263-281.

Novick, J. M., Hussey, E., Teubner-Rhodes, S. E., Harbison, J. H. \& Bunting, M. F. (2014). Clearing the garden-path: Improving sentence processing through cognitive control training. Language, Cognition and Neuroscience, 29(2), 186217.

Paap, K. R. \& Greenberg, Z. I. (2013). There is no coherent evidence for a bilingual advantage in executive processing. Cognitive Psychology, 66, 232-258.

Pickering, M. J. \& Branigan, H. P. (1998). The representation of verbs: evidence from syntactic priming in language production. Journal of Memory and Language, 39 (4), 633-651.

Pickering, M. J. \& Garrod, S. (2004). Toward a mechanistic psychology of dialogue. Behavioral and Brain Sciences, 27(2), 169-226.

Prior, A. \& MacWhinney, B. (2010). A bilingual advantage in task switching. Bilingualism: Language and Cognition, 13, 253-262. 
Rappaport-Hovav, M. \& Levin, B. (2008). The English dative alternation: The case for verb sensitivity. Journal of Linguistics, 44, 129-167.

Roelofs, A. (1992). A spreading-activation theory of lemma retrieval in speaking. Cognition, 42, 107-142.

Rowland, C. F., Chang, F., Ambridge, B., Pine, J. M. \& Lieven, E. V. M. (2012). The development of abstract syntax: Evidence from structural priming and the lexical boost. Cognition, 125(1), 49-63.

Schoonbaert, S., Hartsuiker, R. J., \& Pickering, M. J. (2007). The representation of lexical and syntactic information in bilinguals: Evidence from syntactic priming. Journal of Memory and Language, 56(2), 153-171.

Shallice, T. (1988). From neuropsychology to mental structure. Cambridge: Cambridge University Press.

Sorace, A. (2016). Language and cognititon in bilingual production: The real work still lies ahead. Bilingualism: Language and Cognition. doi:10.1017/S1366728916000110. Published online by Cambridge University Press, March 2016.

Stephens, N. (2010). Given-before-new: the effects of discourse on argument structure in early child language. Ph.D. Dissertation, Stanford University.

Teubner-Rhodes, S. E., Mishler, A., Corbett, R., Andreu, L., Sanz-Torrent, M., Trueswell, J. C. \& Novick, J. M. (2016). The effects of bilingualism on conflict monitoring, and garden-path recovery. Cognition, 150, 213-231.

Treccani, B., Argyri, E., Sorace, A. \& Della Sala, S. (2009). Spatial negative priming in bilingualism. Psychonomic Bulletin \& Review, 16, 320-327. 
Tungseth, M. E. (2006). Verb preposition in Norwegian: Paths, Places and Possession. Ph.D. Dissertation, UiT, the Arctic University of Norway.

Unsworth, S. (2011). Utrecht Bilingual Language Exposure Calculator. University of Utrecht.

Valian, V. (2015). Bilingualism and cognition. Bilingualism: Language and Cognition, 18(1), 3-24.

Vasilyeva, M., Waterfall, H., Gámez, P. B., Gómez, L. E., Bowers, E., \& Shimpi, P. (2010). Cross-linguistic structural priming in bilingual children. Journal of Child Language, 37, 1047-1064.

Westergaard, M. \& Anderssen, M. (2015). Word order variation in Norwegian possessive constructions: bilingual acquisition and attrition. In J. Bondi Johannessen \& J. Salmons (eds.). German heritage languages in North America: Acquisition, attrition and change, pp. 21-45. Amsterdam: John Benjamins

Zelazo, P. D. \& Frye, D. (1998). Cognitive complexity and control: The development of executive function in childhood. Current direction in psychological science, 4(7), $121-126$. 